\title{
Huge aneurysmal bone cyst secondary to giant cell tumor of the hand phalanx: a case report and related literature
}

\author{
Mingzhuo Li ${ }^{1}$, Yaokai Gan², Dingwei Shi ${ }^{2}$ and Jie Zhao ${ }^{2}$
}

\begin{abstract}
Background: Aneurysmal bone cyst (ABC) secondary to Giant Cell Tumor of bone (GCT) is a rare lesion, of which the incidence is about 0.011 to 0.053 per 100,000 every year. There are only a few previous case reports, and most of them occur in the spine, long bones or flat bones.

Case presentation: We report one case of a patient who complained of "progressive enlargement of the mass on right-hand fifth finger for 5 years with ulceration for 6 months". After the imaging examination in our hospital, it was diagnosed as a "huge bone tumor on the proximal phalanx of the right-hand fifth finger", then wide excision and amputation of the fifth finger were made. The pathological examination diagnosed the mass as aneurysmal bone cyst secondary to giant cell tumor, $13 \times 8 \times 6 \mathrm{~cm}^{3}$, with no local infiltration observed. No recurrence and metastasis occurred 18 months after the operation, and the patient recovered well.
\end{abstract}

Conclusion: In this report, we discuss the etiology, diagnosis, differentiation, and management of Aneurysmal bone Cyst secondary to Giant Cell Tumor of bone, and review previous case studies.

Keywords: Giant Cell Tumor of bone, Aneurysmal bone Cyst, hand short bone, huge bone tumor

\section{Background}

Giant cell tumor (GCT) of bone is a locally invasive tumor, mostly benign, but with a distant metastasis rate of $2 \%$ [1]. It is a common benign lesion in Asian, accounting for about $20 \%$ of all primary bone tumors. Most of GCTs arise in the epiphysis and are commonly found in the distal femur, proximal humerus, proximal femur, and distal tibia. Only about $0.5 \%$ occur in the hand [2], but the recurrence rate of them is higher than that in other parts [3]. Aneurysmal bone cysts (ABCs) account for about 5 to $6 \%$ of benign bone tumors [4] and mostly occur in young people before the age of 20 . $\mathrm{ABCs}$ are considered primary lesions in approximately $70 \%$ of cases, with the remaining $30 \%$ arising secondary

\footnotetext{
* Correspondence: ganyk2004@126.com

${ }^{2}$ Shanghai Ninth People's Hospital, Shanghai Jiao Tong University School of Medicine, Shanghai, China

Full list of author information is available at the end of the article
}

to different primary tumors. GCT is the most common primary lesion to secondary ABCs, accounting for 19 to $39 \%$ [5], and about $80 \%$ of GCT secondary to ABC occur in spine, long bones or flat bones [6]. According to the literature, there are few cases of GCT secondary to $A B C$ occurring in the short bones of the hands or feet. This patient has a long course of the disease, the tumor is huge, and its clinical manifestation is not obvious. Additionally, the early stage is easily confused with other bone diseases such as tophus, so the article reviews and analyzes this case.

\section{Case presentation}

A 57-year-old man found a small mass on the proximal phalanx of the right fifth finger 5 years before. It was initially peanut-sized and slowly progressing without any discomfort like pain. About 1 year before, the mass increased rapidly and the patient went to another hospital 
after half a year. Because of the gout history of the patient, the doctor considered the mass tophus, but no obvious effect appeared after drug therapy. 2 months before, the mass has swollen to $13 \times 8 \times 6 \mathrm{~cm}^{3}$ (Fig. 1). The surface was partially broken, with no pain, no neuralgia, no sensory disorder, no headache or dizziness, no chest stuffy or shortness of breath, no nausea or vomiting, etc. It was initially diagnosed as a "huge bone tumor on the proximal phalanx of the right-hand fifth finger". The patient has a history of smoking and drinking.

Upon physical examination, the mass on the ulnar of proximal interphalangeal joint of right-hand fifth fingers was about $13 \times 8 \times 6 \mathrm{~cm}^{3}$, tough touched, with slight tenderness, surface ulceration, a little bloody exudation, and no purulent secretions. The skin over the mass was warm, and the feeling and movement of the finger were normal. The axillary lymph nodes and supraclavicular lymph nodes were not swollen. The remaining bones of the limbs had no subcutaneous nodules. The liver and spleen were of normal sizes and there was no abnormality in the heart, lung, and brain.

$\mathrm{X}$-ray plain (Fig. 2) of the right upper limb was performed. Right-hand fifth finger proximal phalanx bone destruction was seen, with swelling, bubble-like changes and local reticular shadow, accompanied by soft tissue swelling. Adjacent phalanx bone structure stayed clear.

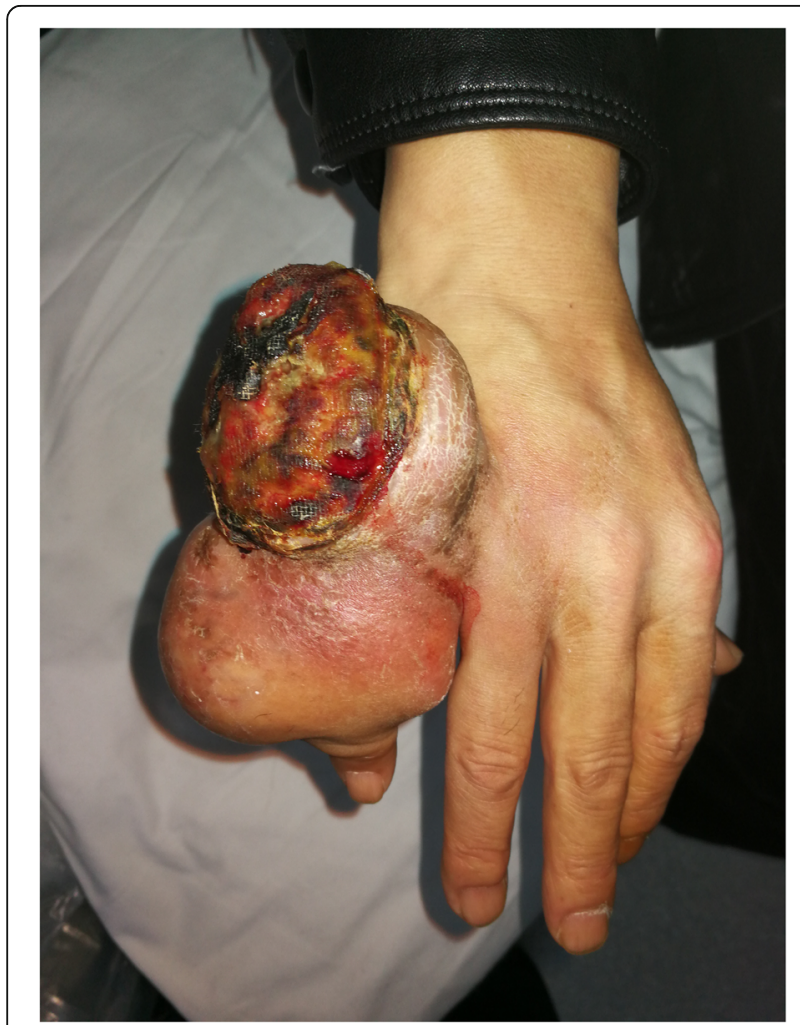

Fig. 1 A huge mass can be seen at the proximal of right hand fifth finger, about $13 \times 8 \times 6 \mathrm{~cm} 3$, the surface collapsed, with a little bloody exudation

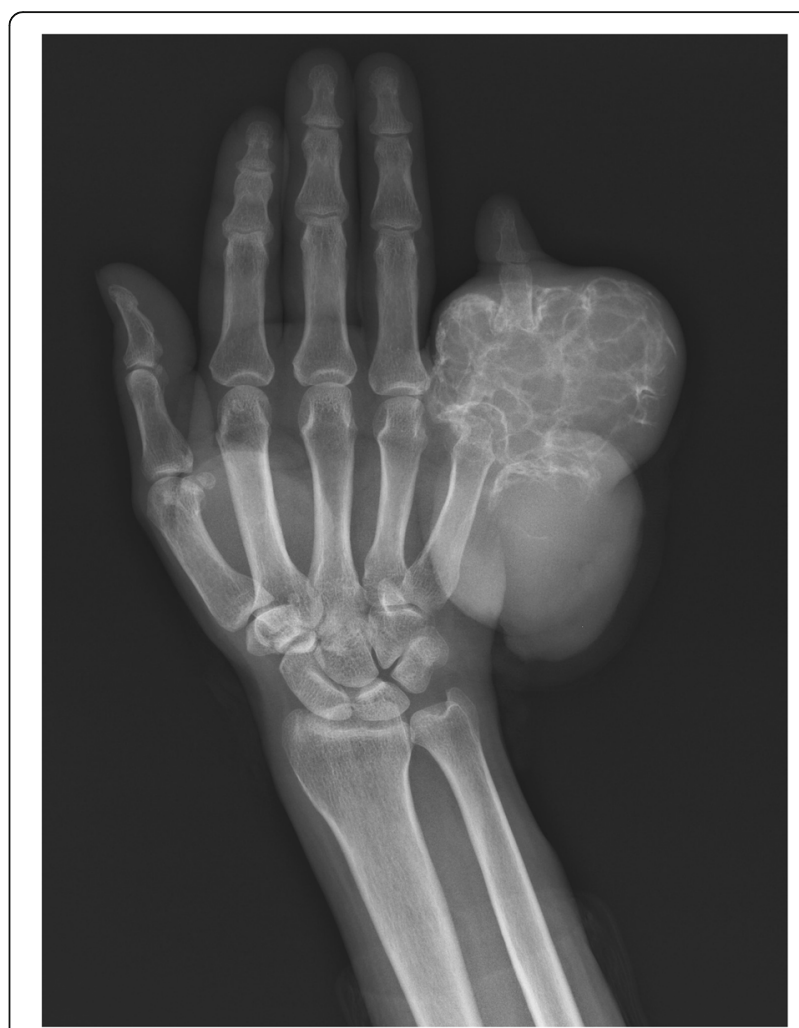

Fig. $2 \mathrm{X}$-ray plain shows bone destruction, with swelling, bubble-like changes and local reticular shadow, accompanied by soft tissue swelling

Computed tomography (CT) three-dimensional imaging (Figs. 3 and 4) showed the mass on the right-hand fifth finger was about $8.6 \times 6.3 \times 5.8 \mathrm{~cm} 3$. The bone shell was thin. The multilocular cystic division and multiple low-density shadows were seen. Osteolysis and bone mineralization existed simultaneously. Part of the bone cortex was discontinuous, but the periosteal reaction was not obvious. A soft tissue mass was prominently deserved and the density of it was uneven, for the CT value was from 13 to $45 \mathrm{HU}$. The marginal part of mass bypassed the proximal interphalangeal joint and invaded the right middle fifth phalanx. It is a pity that MRI was not taken. X-ray of the chest revealed no pulmonary metastasis. Following laboratory tests, the blood uric acid was observed to be at $400 \mathrm{umol} / \mathrm{L}$ and other test results were almost within the normal ranges.

The right-hand fifth finger interception combined with giant bone tumor resection was taken under the general anesthesia. Intraoperatively, the fifth metacarpal, phalanx, and tumor were completely removed. Histopathological findings revealed features of GCT with ABC (Figs. 5 and 6). As we can see, there are lots of mononuclear ovoid cells and multinucleated giant cells, and the big cell nuclei of them are mostly vacuolar. In another picture, the capsule wall of aneurysmal bone cyst 


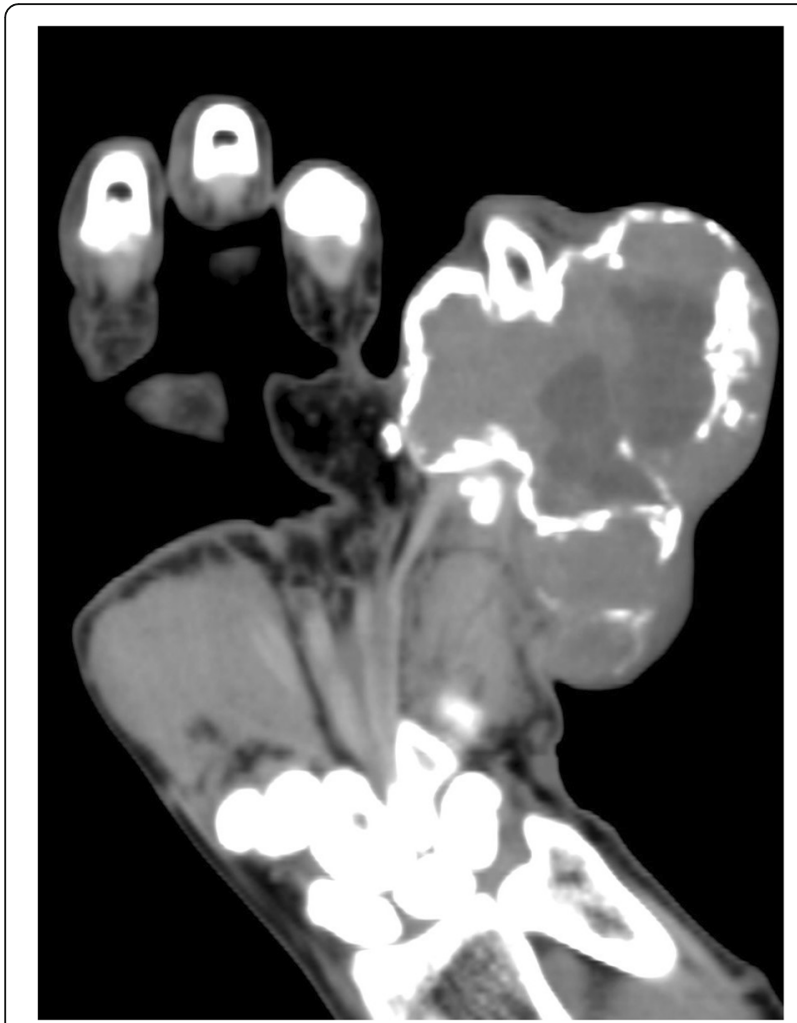

Fig. 3 Coronal CT shows swelling changes, the bone shell is thin. The multilocular cystic division and multiple low-density shadows was seen

and many small vessel walls can be seen, which is the feature of ABCs. Macroscopically, the resected tumor tissue was grey, red and white; no necrosis was observed. Microscopically, the resected margin was tumor-free. Immunohistochemistry results indicated that the tumor cells were partly positive for Vim, KP-1, PGM-1, and CD34, and negative for Des, MSA, P63, and CD45. The Ki67 was about $10 \%$.

Following surgery, the patient's vital signs were stable, and there was a small amount of exudation in the surgical incision. Due to the high skin tension of the local suture, the wound healing was a little poor, but the blood supply of fingertips was good. After several dressing changes the wound improved. No radiotherapy and chemotherapy were required, for the pathology suggested a benign change. Every one-month follow-up observation was required, clinical and radiological examinations, including palpation and plain radiography, were performed. No local recurrence or distant metastasis were identified 18 months following surgery. The patient is in a good position now.

\section{Discussion and Conclusions}

Giant cell tumor of bone is a common local invasive tumor, mostly benign, accounting for $5 \%$ of all primary bone tumors in the Western population, and only $2-5 \%$ occurs in the phalanges [6]. Athanasian reported 13 cases of giant cell tumor on the phalanges, the clinical manifestation was mainly swelling (85\%) and pain (62\%), and some were found through physical examination (54\%), fewer patients got pathological fractures (9\%) [3]. Wold and Swee pointed out 13\% of patients had multicentric giant-cell tumor [7]. Two of the 28 patients with giant cell tumor of the phalanx reported by Averill et al. had lung metastases [8]. Therefore, the CT of the chest and whole-body bone scans are considered as necessary examinations for the patient.

Histologically, giant cell tumor of bone is composed of mononuclear ovoid and spindle-shaped cells associated with multinucleated giant cells and macrophages [6]. The lesions were graded according to the appearance of the stroma and the giant-cells. Averill [8] et al. reported 28 cases, of which 12 were grade I, 3 were mixed of grade I and II, 4 were grade II and 9 were grade III. Among the common treatments, the recurrence rate of curettage alone or curettage with bone grafting was $79 \%$, and the recurrence rate of local resection and bone grafting, ray resection or amputation was $36 \%$. Radiation resection and extensive resection are deemed to be the most effective methods [8].

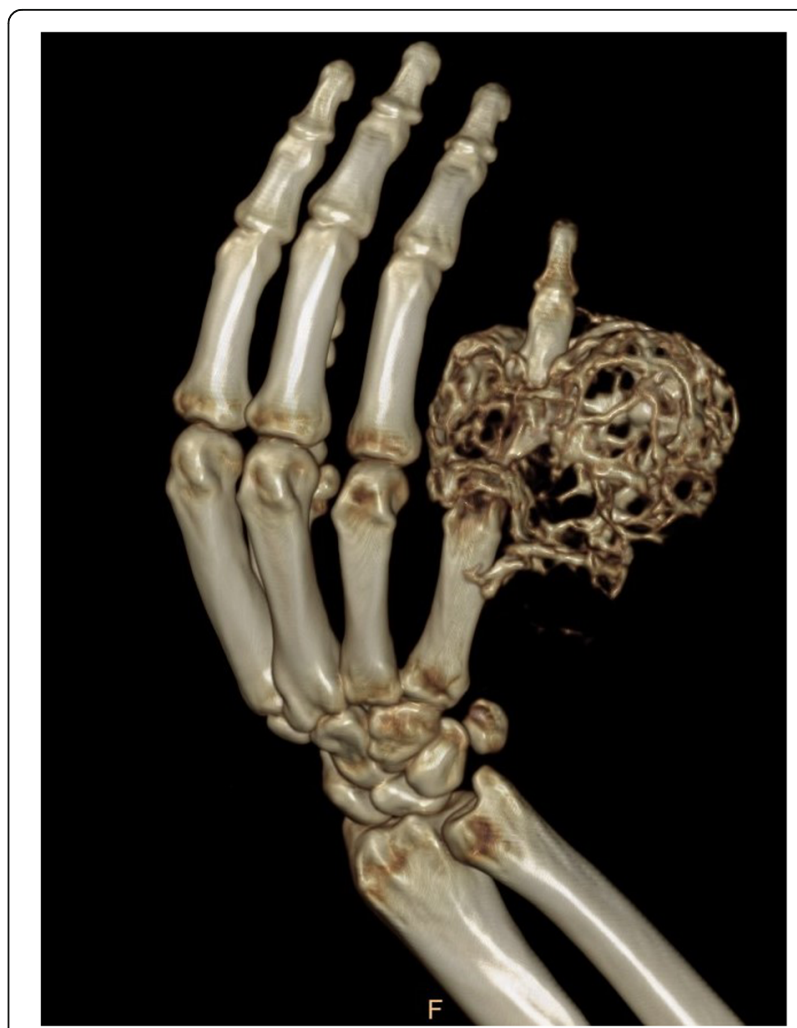

Fig. 4 CT three-dimensional reconstruction showed soap bubblelike, swelling changes, osteolysis and bone mineralization existed simultaneously 


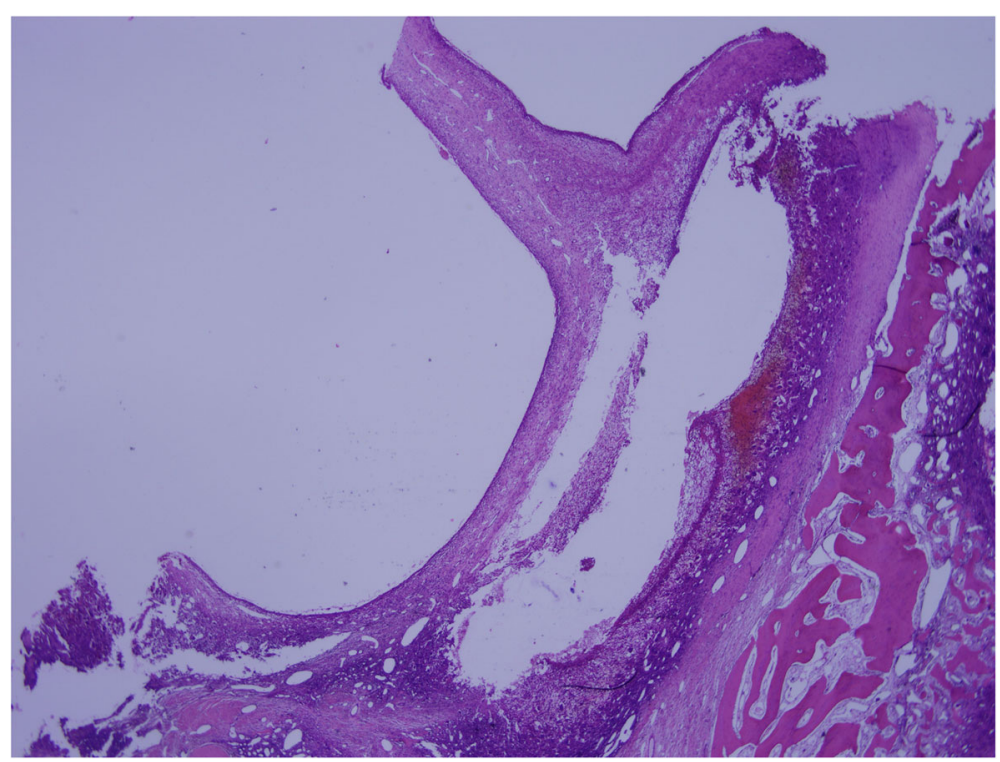

Fig. 5 Pathology shows giant cell tumor of bone with aneurysmal bone cyst, the wall of the aneurysm can be seen $(x 20)$

Aneurysmal bone cyst $(\mathrm{ABC})$ was first described by Jaffe and Lichtenstein [9] in 1942 and was named for its pathological manifestations. Histologically, it is characterized by a cavernous vascular tumor ranging from a few millimeters to 1 to $2 \mathrm{~cm}$ in diameter, with intralesional communicating cavitations without blood clots. Typically, microscopic analysis of $A B C$ reveals hemorrhagic tissue with cavitary spaces separated by fibrous septa composed of spindle cells, inflammatory cells, and a smaller percentage of giant cells [10]. Aneurysmal bone cyst is a benign, osteolytic, expansive, hemorrhagic and mostly solitary lesion, accounting for about 5 to $6 \%$ of benign bone tumors.
Aneurysmal bone cysts can occur in bones throughout the body, especially in long bones (67\%), spine (15\%), and pelvis (9\%). Frassica et al. reported 10 cases of $A B C$ on phalanx, usually, patients felt pain (90\%) and swelling (40\%) and a few pathological fractures happened (10\%) [11].

At present, the treatments of primary aneurysmal bone cysts mainly include nutritional vascular embolization, lesion scraping, surgical resection, and autologous bone transplantation. In the report of Frassica et al., the recurrence rate of lesion scraping and autologous bone graft is high, about $57.1 \%$. 3 patients with complete bone resection and no recurrence happened [11].

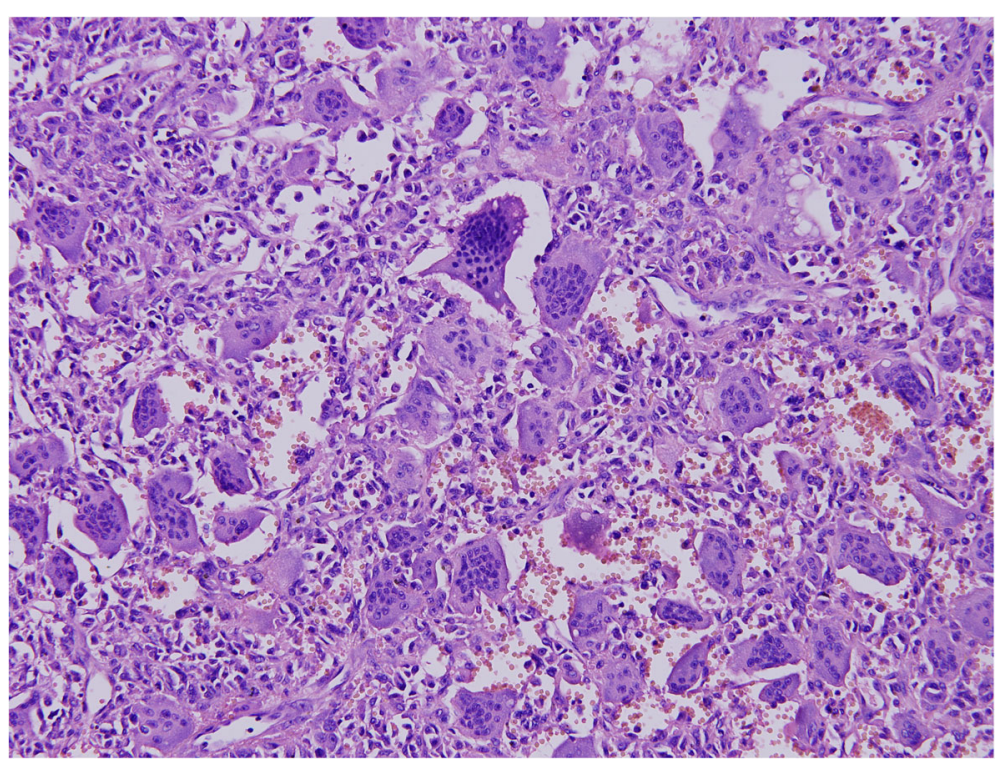

Fig. 6 The giant cell tumor-like changes can be seen $(\times 200)$, and the arrows refer to the bone giant cells 
Aneurysmal bone cyst secondary to giant cell tumor mostly occurs in patients of 20 to 40 years [12]. Recent studies suggest that secondary aneurysmal bone cysts may be related to factors such as hyperemia and dilatation of the vascular bed [13] or induced vascular bed caused by arteriovenous malformation of primary lesions [14]. Patients often present with intermittent pain, soft tissue mass, limited joint activity, etc. The incidence of pathological fracture is larger than that of patients with primary giant cell tumor of the bone [15].

Imaging examination is an important diagnostic tool for GCT and ABC. It is difficult for a simple X-ray examination to find two lesions, so CT and MRI are necessary supplements. CT typically revealed a characteristic soap-bubble appearance, and a balloon-like, multilocular lytic lesion. Pathologic fracture was a common finding. Magnetic resonance (MR) imaging revealed a mass with a fluid-fluid interface with hypointense signals on T1-weighted imaging (T1WI) and hyperintense signals on T2-weighted imaging (T2WI) with contrast enhancement of the septa. The presence of a double density fluid level within the lesion was often seen [12].

Histopathologically, ABC secondary to GCT shows two lesions at the same time microscopically, which is the basis for diagnosis. The treatment of $\mathrm{ABC}$ secondary to GCT is usually focused on the treatment of the bone giant cell tumor. The surgical method should be determined according to the degree of malignancy, location and peripheral invasion or not of bone giant cell tumor [16].

Identification with finger tophus: tophus is the white crystalline substance within the subcutaneous tissues or associated with joints and tendons, which can infiltrate the joint or tendon tissue and show sodium urate crystal under polarized light microscopy [17]. Typical sites for tophus deposition are well recognized including the olecranon bursa, the Achilles tendon, the first metatarsophalangeal joint, the ear and the finger pulps. The tophus is often multiple [18] and can cause joint damage, ankylosis, and others. Tophus is usually found in patients with a history of gout for more than 10 years without treatment [16]. On the X-ray plain, the tophus is often characterized by joint destruction, soft tissue swelling around the joint, and local uplift. In this case, the patient got hyperuricemia about 4 years ago. The location and clinical manifestations of the mass were similar with those of tophus. But such a huge tumor didn't erode the joint, and the other limbs had no subcutaneous nodules, which can be the point distinguishing from tophus.

Differentiation from primary malignancy in giant cell tumor of bone (PMGCT): As is reported by Franco Bertoni [19], PMGCT is extremely unusual, there are only 5 PMGCTs in 924 patients diagnosed by GCT. Pain (4 cases) and swelling ( 2 cases) were the most common symptoms of the malignancies. All PMGCTs appeared on plain films as osteolytic lesions with wellcircumscribed margins in the epiphyses of long bones. An area of less distinct margins was present in two cases, and cortical breakthrough was observed in four cases. A soft tissue mass was seen on plain films in two of the five cases. In this case, the mass grows rapidly in the last year, and the clinical manifestations are similar with those of osteosarcoma. The density of lesion on CT is uneven, bone destruction and bone regeneration exist at the same time, so the mass may be diagnosed as the malignant bone tumor. However, there is no obvious periosteal reaction on the X-ray plain. The possibility of malignant transformation may be low, and the diagnosis can be confirmed by pathological examination.

In summary, medical history and imaging examination are the main methods to identify the $\mathrm{ABC}$ secondary to GCT. The pathological examination is the gold standard. The surgical method should be determined according to the state of bone giant cell tumor. This paper reports a rare case of $\mathrm{ABC}$ secondary to GCT on the phalanx, hoping to provide experience for early diagnosis and treatment.

\section{Abbreviations \\ ABC: Aneurysmal bone Cyst; GCT: Giant Cell Tumor;" CT: Computed tomography; MRI: Magnatic Resonance Imaging; US: Ultrasonography; DECT: Dual-energy computed tomography; PMGCT: Primary malignancy in giant cell tumor of bone; VIM: Vimentin; PGM-1: Phosphoglucomutase-1; CD34: Cell differentiation-34; MSA: Multiplication-stimulating factor}

\section{Acknowledgements}

Our work is supported by Shanghai Ninth People's Hospital and Medical School of Shanghai Jiaotong University. We thank our patient who kindly gave his consent for this publication. We thank Editorial Office of BMC Cancer for editing the revised version.

\section{Authors' contributions}

Conception and design: GYK; Manuscript writing: LMZ; Final approval: GYK, SDW, ZJ; Pathological explorations: CY; Patient's management: GYK, SDW. All authors read and approved the final manuscript.

\section{Funding}

This study was supported by Shanghai Ninth People's Hospital and Medical School of Shanghai Jiaotong University. The funders have no role in the study except for financial support.

\section{Availability of data and materials}

The data that support the findings of this study are available from Shanghai Ninth People's Hospital, but restrictions apply to the availability of these data which were used under license for the current study, and so are not publicly available. Data are however available from the authors upon reasonable request and with permission of Shanghai Ninth People's Hospital. We make sure identifying/confidential patient data should not be shared.

\section{Ethics approval and consent to participate}

We have got the patient's informed consent, and the agreement of Institutional Ethic Committee Office of Shanghai Ninth People's Hospital. The number is SH9H-2019-T49-1.

\section{Consent for publication}

Written informed consent was obtained from the patient for publication of this case report and any accompanying images. A copy of the written consent is available for review by the Editor of this journal. 


\section{Competing interests}

The authors declare that they have no competing interests.

\section{Author details}

'Shanghai Sixth People's Hospital, Shanghai Jiao Tong University School of Medicine, Shanghai, China. ${ }^{2}$ Shanghai Ninth People's Hospital, Shanghai Jiao Tong University School of Medicine, Shanghai, China.

Received: 18 July 2019 Accepted: 12 March 2020

Published online: 19 March 2020

\section{References}

1. Biermann JS, Adkins DR, Agulnik M, Benjamin RS, Brigman B, Butrynski JE, Cheong D, Chow W, Curry WT, Frassica DA, et al. Bone cancer. J Natl Compr Cancer Netw. 2013;11(6):688-723.

2. Niu X, Zhang $Q$, Hao L, Ding Y, Li Y, Xu H, Liu W. Giant cell tumor of the extremity: retrospective analysis of 621 Chinese patients from one institution. J Bone Joint Surg Am. 2012;94(5):461-7.

3. Athanasian EA, Wold LE, Amadio PC. Giant cell tumors of the bones of the hand. J Hand Surg. 1997;22(1):91-8.

4. Errani C, Ruggieri P, Asenzio MAN, Toscano A, Colangeli S, Rimondi E, Ross G, Longhi A, Mercuri M. Giant cell tumor of the extremity: a review of 349 cases from a single institution. Cancer Treat Rev. 2010;36(1):1-7.

5. Rapp TB, Ward JP, Alaia MJ. Aneurysmal bone cyst. J Am Acad Orthop Surg. 2012;20(4):233-41.

6. Vergel De Dios AM, Bond JR, Shives TC, McLeod RA, Unni KK. Aneurysmal bone cyst. A clinicopathologic study of 238 cases. Cancer. 1992;69(12):2921-31.

7. Wold LE, Swee RG. Giant cell tumor of the small bones of the hands and feet. Semin Diagn Pathol. 1984;1(3):173-84.

8. Averill RM, Smith RJ, Campbell CJ. Giant-cell tumors of the bones of the hand. J Hand Surg. 1980;5(1):39-50.

9. Jaffe HL, Lichtenstein L. Benign Chondroblastoma of bone: a reinterpretation of the so-called calcifying or Chondromatous Giant cell tumor. Am J Pathol. 1942;18(6):969-91.

10. Dabska M, Buraczewski J. Aneurysmal bone cyst. Pathology, clinical course and radiologic appearances. Cancer. 1969;23(2):371-89.

11. Frassica FJ, Amadio PC, Wold LE, Beabout JW. Aneurysmal bone cyst: clinicopathologic features and treatment of ten cases involving the hand. J Hand Surg. 1988;13(5):676-83.

12. Wu Z, Yang X, Xiao J, Feng D, Huang Q, Zheng W, Huang W, Zhou Z. Aneurysmal bone cyst secondary to giant cell tumor of the mobile spine: a report of 11 cases. Spine (Phila Pa 1976). 2011;36(21):E1385-90.

13. Patel PJ, Demos TC, Lomasney LM, Rapp T. Your diagnosis? Aneurysmal bone cyst. Orthopedics. 2005;28(5):428-511.

14. Arora SS, Paul S, Arora S, Kapoor V. Secondary jaw aneurysmal bone cyst (JABC)--a possible misnomer? A review of literature on secondary JABCs, their pathogenesis and oncogenesis. J Oral Pathol Med. 2014;43(9):647-51.

15. Song M, Dai W, Sun R, Liang H, Liu B, Wu Y, Ma K, Lu M. Giant cell tumor of the patella with a secondary aneurysmal bone cyst: a case report. Oncol Lett. 2016;11(6):4045-8.

16. Anchan C. Giant cell tumor of bone with secondary aneurysmal bone cyst. Int J Shoulder Surg. 2008;2(3):68.

17. Chhana A, Dalbeth N. The gouty tophus: a review. Curr Rheumatol Rep. 2015:17(3):19.

18. Walke V, Ramraje S, Jadhao V. Cytodiagnosis of gouty tophus. Cytojournal. 2013;10:11.

19. Bertoni F, Bacchini P, Staals EL. Malignancy in giant cell tumor. Skelet Radiol. 2003;32(3):143-6.

\section{Publisher's Note}

Springer Nature remains neutral with regard to jurisdictional claims in published maps and institutional affiliations.

Ready to submit your research? Choose BMC and benefit from:

- fast, convenient online submission

- thorough peer review by experienced researchers in your field

- rapid publication on acceptance

- support for research data, including large and complex data types

- gold Open Access which fosters wider collaboration and increased citations

- maximum visibility for your research: over $100 \mathrm{M}$ website views per year

At $\mathrm{BMC}$, research is always in progress.

Learn more biomedcentral.com/submissions 